ARTICLE

\title{
Extendable stapling of unprotected peptides by crosslinking two amines with o-phthalaldehyde
}

\author{
Bo Li ${ }^{1}$, Lan Wang ${ }^{1}$, Xiangxiang Chen ${ }^{1}$, Xin Chu' ${ }^{1}$, Hong Tang${ }^{1}$, Jie Zhang ${ }^{2}$, Gang He (i) ${ }^{1}$, Li Li (i) ${ }^{2 凶}$ \& \\ Gong Chen (1) ${ }^{1 \times}$
}

Peptide modification methods that do not rely on the cysteine residue are underdeveloped, and their development could greatly expand the current toolbox for peptide chemistry. During the course of preliminary investigations into the classical ortho-phthalaldehyde (OPA)-aminethiol condensation reaction, we found that in the absence of thiol, OPA readily condenses with two primary alkyl amines to form a class of underexplored isoindolin-1-imine compounds under mild aqueous conditions. From the intramolecular version of this OPA-2amines reaction, an efficient and selective methodology using mild reaction conditions has been developed for stapling unprotected peptides via crosslinking of two amino groups in both an end-to-side and side-to-side fashion. The stapling method is superfast and broadly applicable for various peptide substrates with the reacting amino groups separated by a wide range of different amino acid units. The macrocyclization reactions of selected substrates are completed within 10 seconds at $5 \mathrm{mM}$ concentration and within 2 minutes at $50 \mu \mathrm{M}$ concentration. Importantly, the resulting cyclized peptides with an isoindolinimine linkage can be extended in a one-pot sequential addition manner with several different electron-deficient $\pi$ electrophiles, thereby generating more complex structures.

\footnotetext{
${ }^{1}$ State Key Laboratory and Institute of Elemento-Organic Chemistry, College of Chemistry, Nankai University, Tianjin 300071, China. ${ }^{2}$ Beijing Key Laboratory of Active Substances Discovery and Druggability Evaluation, Institute of Materia Medica, Chinese Academy of Medical Sciences, Peking Union Medical

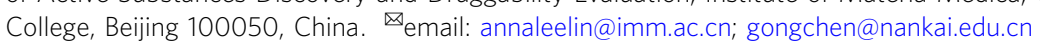


$\mathrm{T}$ here is increasing recognition of the importance of peptides in drug discovery ${ }^{1}$. However, to modulate their structures and physiochemical properties, further modification of natural peptides or those generated by the standard synthetic protocols is usually required ${ }^{2,3}$. In this regard, the chemoselective crosslinking or stapling of two peptide handles has proven to be highly effective for the macrocyclization of peptides into more conformationally constrained versions ${ }^{4-9}$. Traditional approaches, which have been successful in the past, have involved bioorthogonal coupling reactions using noncanonical amino acid (AA) units, such as alkyne-azide cycloaddition and metalcatalyzed alkene metathesis. However, an approach that would involve the stapling of native peptides in their unprotected form would be much more desirable owing to the easy accessibility of such substrates and their high compatibility with biological systems ${ }^{10-14}$. Most of the research thus far has focused on the linking of highly reactive cysteine (Cys) residues (Fig. 1a) ${ }^{15-21}$. A commonly used peptide stapling technique involves the bisalkylation or arylation of two Cys residues with linkers bearing two electrophilic sites. Recently, the groups of $\mathrm{Li}$ and Perrin independently reported a powerful method for the macrocyclization of native peptides between Cys and lysine (Lys) residues using a simple ortho-phthalaldehyde (OPA) reagent (Fig. 1b) ${ }^{22,23}$. While Cys has proven to be a very reliable anchor for peptide modification, it is often absent from the accessible peptides of interest and needs to be incorporated by additional synthetic manipulations. The current toolbox for stapling native peptides could be greatly expanded by exploring other common amino acid residues as potential cross-linking anchors ${ }^{24-28}$. Useful methods for such noncysteine stapling are still very scarce ${ }^{5,29-31}$. Here, we show that the primary amino groups from two AA residues can undergo a condensation reaction with OPA as the linker, forming a class of underexplored isoindolinimine structures under mild aqueous conditions (Fig. 1c). This chemoselective intramolecular OPA-2amines reaction resulted in the fast and efficient macrocyclization of native peptides in both $\mathrm{N}$-end to side chain (end-to-side) and side chain to side chain (side-to-side) fashions under mild aqueous conditions with a broad substrate scope. Moreover, the resulting isoindolinimine linkage allows further extension via a one-pot process by reaction with various $\pi$ electrophiles in high efficiency and selectivity, allowing secondary and even tertiary modification as well as the rapid construction of complex structures.

\section{Results}

Reinvestigation of the OPA-amine condensation reaction. OPA has been used as a color and fluorescence indicator for sensing ammonia and amine compounds, such as $\alpha$-amino acids (AAs) for over a century ${ }^{32,33}$. In 1909, Thiele was the first to report the formation of isoindolin-1-one $\mathbf{1}$ (also called phthalimidine) by the reaction of OPA with aniline in an organic solvent at room temperature (rt) (Fig. 2a) $)^{34}$. The reaction of OPA with amines proceeds by initial formation of the cyclic hemiaminal 2, yielding iminium intermediate 3 after the loss of water. Several mechanisms, including protonation of isoindolinol intermediate 4 , a $[1,3]$ hydride shift, and the $[1,3]-\mathrm{H}$ sigmatropic rearrangement of $\mathbf{3}$, have been proposed for the conversion of 3 to $\mathbf{1}^{35-37}$. The significance of the OPA-amine reaction was recently demonstrated by $\mathrm{Li}$ for the selective modification of Lys in peptides and proteins ${ }^{38}$. In the seminal discovery by Roth from 1970, it was found that a mixture of OPA, primary amine, and 2-mercaptoethanol quickly reacted in an alkaline aqueous medium to afford a strongly fluorescent product (Fig. 2b) ${ }^{39}$, which was later identified by Simons as the 1-thio-isoindole $\mathbf{5}^{40}$. Simons subsequent discovery that 5 reacted with dimethyl acetylenedicarboxylate (DMAC) to form a 1-thio-3-alkenylisoindole addition product with high efficiency hinted at the usefulness of this reaction type for further functionalization ${ }^{41}$. The three-component OPA-amine-thiol condensation reaction is believed to proceed through cyclic intermediate 6, which undergoes dehydration to form 5 . a)
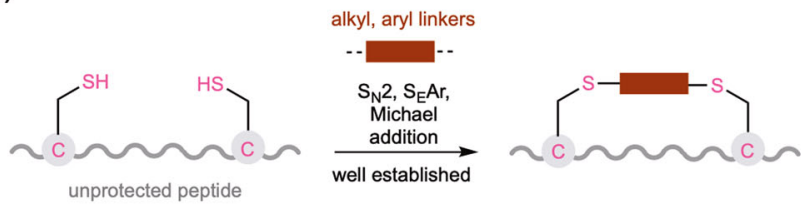

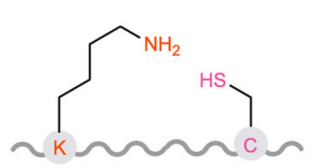

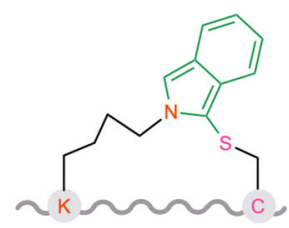

Li, Perrin

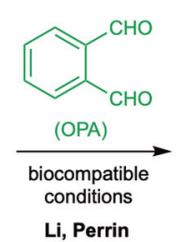

c)

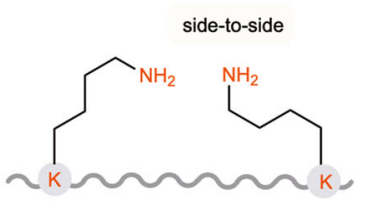

unprotected peptide

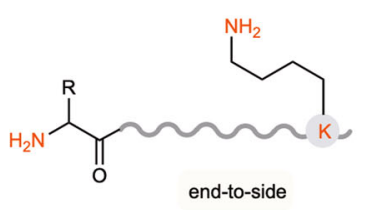

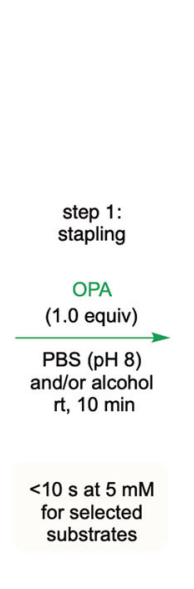
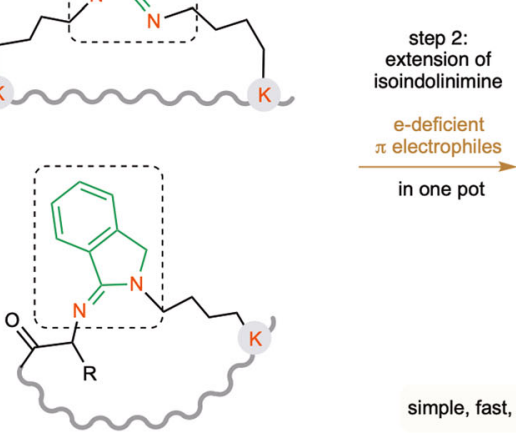
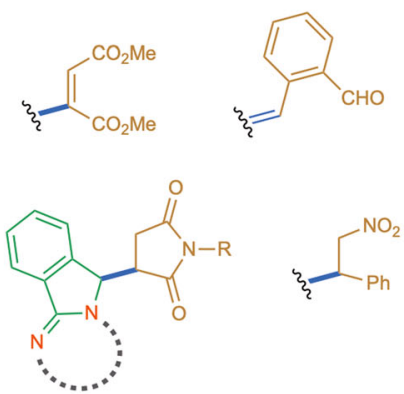

Fig. 1 Stapling of unprotected peptides via non-Cys residues under mild aqueous conditions. a Common strategies for peptide stapling via two cysteine residues. b OPA-mediated peptide stapling via cysteine and lysine residues. c OPA-mediated peptide stapling via two amine groups (this work). C:

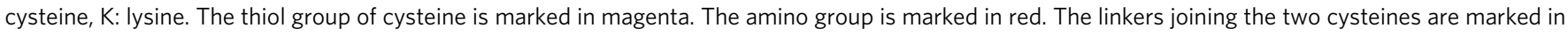

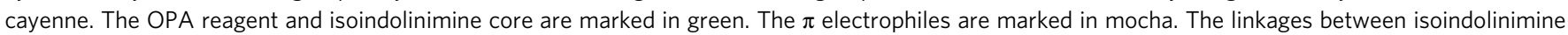
and electrophiles are marked in blue. 
a)

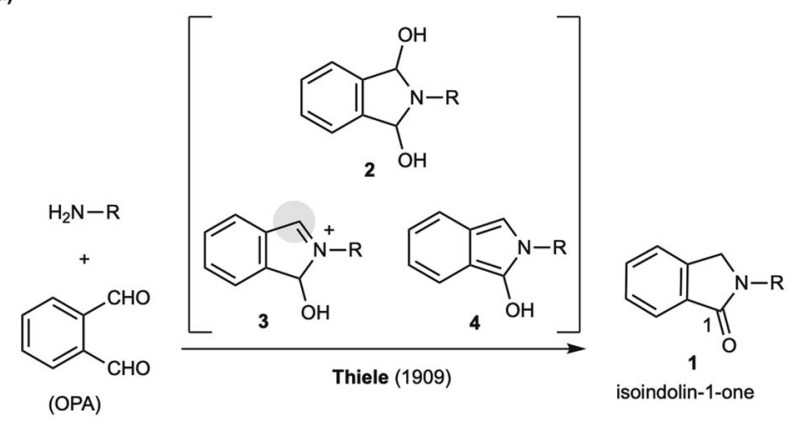

b)

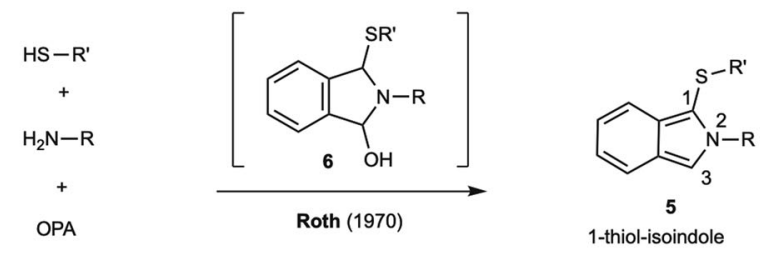

c)

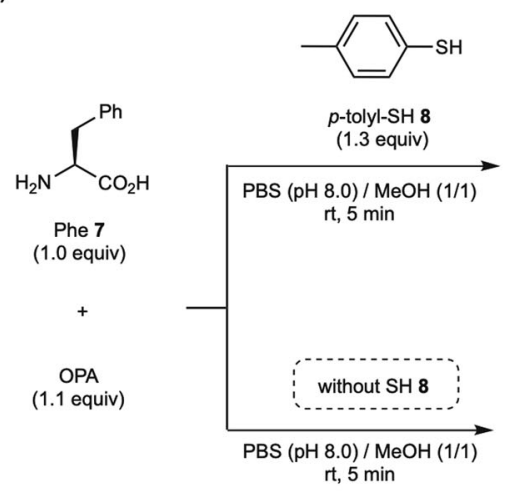

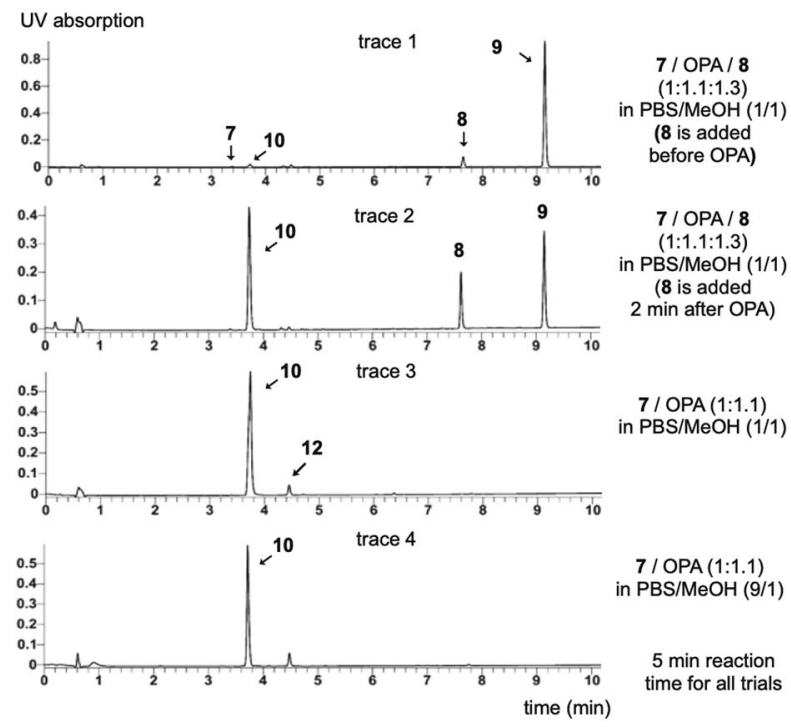

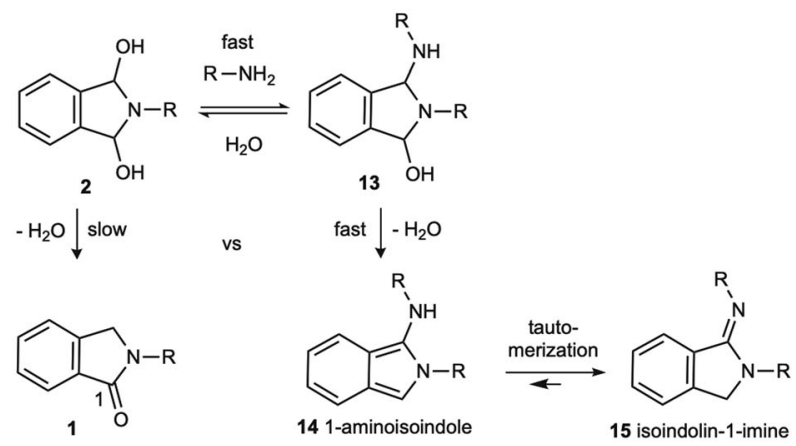<smiles></smiles><smiles>O=C1c2ccccc2CN1C(O)CCP</smiles>

11 (not formed)<smiles>CNc1c2ccccc2cn1C(O)Cc1ccccc1</smiles>

f)

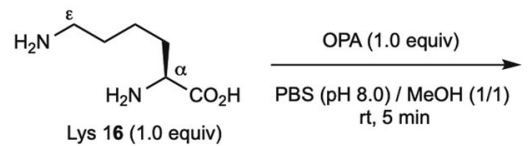<smiles>O=C(O)C1CCCCN2Cc3ccccc3C1=N2</smiles>

$17 a, 81 \%$

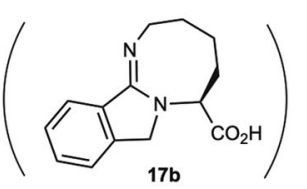

Fig. 2 Reinvestigation of the OPA-amine condensation reaction under mild aqueous conditions in the presence and absence of thiol. a Two-component reaction (OPA-amine). b Three-component reaction (OPA-amine-thiol). c Comparison of reactions of amine and OPA with or without thiol. $\mathbf{d}$ LC-MS analysis of the reaction of Phe $\mathbf{7}$ and OPA with or without thiol $\mathbf{8}$. Unprotected AA substrates, such as Phe $\mathbf{7}$, gave a very weak UV signal on LC analysis. OPA (retention time: 2-3 min) also gave a weak UV signal on LC. e Proposed mechanism for the formation of isoindolin-1-imine. $\mathbf{f}$ Facile end-to-side cyclization of Lys with OPA (OPA-2amines). See Supplementary Figs 1-6 for the NMR-based structure assignment of 17a. All reactions were conducted at a $0.05 \mathrm{mmol}$ scale. Yields were based on an isolated product.

Owing to its rapidity and robustness, the Roth method has gained wide popularity to derivatize AA samples for chromatographic analysis. In addition, it has found usefulness to selectively modify Lys and Cys residues of proteins $s^{42,43}$. For example, Porttoghese developed an OPA- $\beta$-funaltrexamine conjugate as a fluorogenic affinity-labeling ligand of opioid receptors ${ }^{42}$. From these background works, $\mathrm{Li}$ and Perin developed the macrocyclization of unprotected peptides under biocompatible conditions by chemoselectively crosslinking Cys and Lys residues 22,23 . Furthermore, while there is much research mostly prior to 1990 describing the reaction of OPA with various partners in organic solvents, OPA chemistry under mild aqueous conditions that are potentially suitable for biomedical applications has not been vigorously investigated.
Recently, we discovered that the Roth method for HPLC analysis of AA could be repurposed for quantitative chiroptical sensing of AA using UV and circular dichroism (CD) spectroscopy ${ }^{44}$. As shown in Fig. 2c,d, the reaction of phenylalanine 7 (Phe, 1.0 equiv) with OPA (1.1 equiv) and $p$-toluenethiol 8 (1.3 equiv) in a phosphate-buffered saline (PBS) buffer ( $\mathrm{pH} 8.0$ ) and $\mathrm{MeOH}$ solvent mixture at room temperature (rt) quickly formed 1-thio-isoindole product 9 in high yield (see liquid chromatography (LC) trace 1). Besides $\mathrm{MeOH}$, other polar organic solvents, such as $\mathrm{EtOH}, \mathrm{CH}_{3} \mathrm{CN}$, and DMSO, could also be used with success. The enantiomeric excess (ee) value could be determined from the UV and CD spectra of $\mathbf{9}$, rather than by measuring its fluorescence signal. Similar to Roth's original 
study ${ }^{39}$, the fluorescence signal of the reaction mixture was influenced by the addition sequence of the various reagents. If thiol $\mathbf{8}$ was incorporated a couple of minutes after the addition of OPA and Phe 7, the signal was much weaker than if thiol is first added prior to incorporation of OPA. To the best of our knowledge, a detailed explanation for this observation has still not been offered ${ }^{32,33}$, so we set out to further investigate the OPA condensation reactions by LC-MS analysis. As mentioned, delayed addition of thiol 8 to the mixture of OPA and 7 in a 1:1 PBS buffer ( $\mathrm{pH}$ 8.0) and $\mathrm{MeOH}$ solvent mixture led to reduced 9 and formation of the new isoindolinimine adduct $\mathbf{1 0}$, formed from the reaction of one OPA and two Phe molecules (LC trace 2). Moreover, mixing 1.0 equiv of Phe 7 with 1.1 equiv of OPA in the absence of any thiol quickly and selectively formed $\mathbf{1 0}$ as the main product in $5 \mathrm{~min}$ (LC trace 3 ). A minor side product 12 with a molecular weight equivalent to the addition product of 10 and another molecule of OPA (double-OPA product) was generated in a trace amount, while no isoindolin-1-one $\mathbf{1 1}$ was detected. The mechanism for the formation of isoindolinimine likely starts with the reaction of a primary amine with 2 , forming aminal 13 (Fig. 2e). Intermediate 13 dehydrates to generate 1 -aminoisoindole 14, and then quickly tautomerizes to form isoindolin-1-imine 15. If an amine is absent, then 2 slowly dehydrates to give $\mathbf{1}$. As shown in Fig. $2 \mathrm{f}$, Lys $\mathbf{1 6}$ (1.0 equiv) reacts with OPA (1.0 equiv) in a $1: 1$ PBS buffer/MeOH mixture to quickly generate cyclic product 17a in excellent yield and regioselectivity $(\mathbf{1 7 a} / \mathbf{1 7} \mathbf{b}>20 / 1)$, with the structure confirmed by NMR analysis. Such chemoselectivity might be attributed to the intrinsically stronger nucleophilicity of the side chain $\varepsilon$ amine

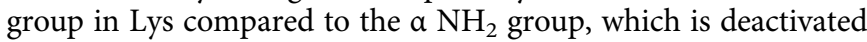
by the electron-withdrawing carboxylate group. The slightly basic conditions and the $\mathrm{MeOH}$ co-solvent might have enhanced the formation of unprotonated Lys side chain in the reaction system $^{45}$.

End-to-side stapling of peptides by OPA-2amines condensation. Having established the condensation reaction of Lys as a proof of concept for the intramolecular condensation between OPA and two amino groups, we next investigated whether the OPA-2amines reaction can be applied in a macrocyclic fashion to crosslink the N-terminal amino group and the Lys side chain of linear peptides (Fig. 3a), easily prepared via solid-phase peptide synthesis (SPPS). We were gratified to find that the model substrate tetrapeptide $\mathrm{H}$-Ala-Trp-Gly-Lys- $\mathrm{NH}_{2} \mathbf{1 8}$ at a $5.0 \mathrm{mM}$ concentration quickly reacted with OPA (1.0 equiv) in a $1: 1$ mixture of PBS ( $\mathrm{pH}$ 8.0) buffer and $\mathrm{MeOH}$ at rt (condition [A]), generating cyclized product $19 \mathrm{a}$ in $77 \%$ yield and with excellent regioselectivity $(\mathbf{1 9 a} / \mathbf{1 9 b}>20 / 1$, see LC trace 5$)$. To our surprise, LC-MS analysis indicated the reaction was completed in less than 10 seconds at $5 \mathrm{mM}$ concentration (LC trace 6). The same reaction of 18 at $50 \mu \mathrm{M}$ was completed within 2 min (see Supplementary Fig. 8). A small amount of side product ( $10 \%$ based on LC estimation) featuring the condensation of 19 a with additional OPA molecule (double OPA product) was formed when the concentration of substrate was increased to $50 \mathrm{mM}$ (see Supplementary Fig. 66). Little intermolecular dimerization product was formed even when the reaction concentration was increased to $100 \mathrm{mM}$. Notably, the $\mathrm{pH}$ value of the medium had a strong impact on the reaction. While the reactions gave very similar results at $\mathrm{pH}$ values between 8.0 and 10.0, the LC yield of 19a slightly dropped to $83 \%$ at $\mathrm{pH} 7.0$ and to $34 \%$ at $\mathrm{pH} 5.0$ along with the significant increase of side product 20 under otherwise identical conditions. Little product was formed at $\mathrm{pH}$ below 3.0 (see Supplementary Fig. 68).
Interestingly, unlike in the reaction of Lys with OPA, lowering the $\mathrm{MeOH}$ content in the solvent mixture to a concentration such as $10 \%$ led to increased formation of the isoindolinone side product 20, along with other unidentified side products (condition [A'], LC trace 7). Other alcohol co-solvents, such as EtOH and trifluoroethanol (TFE), were also effective for promoting the desired macrocyclization. The reaction with DMSO, DMF, $\mathrm{CH}_{3} \mathrm{CN}$, dioxane, or THF as cosolvents gave a considerable amount of $\mathbf{2 0}$ and other side products (see Supplementary Fig. 63 for the detailed evaluation of organic cosolvents). The buffer could be substituted by adding diisopropylethylamine (DIPEA, 3 equiv, for neutralization of the residual TFA in peptide substrate) to a $1: 1$ mixture of $\mathrm{H}_{2} \mathrm{O}$ and $\mathrm{MeOH}$, also efficiently generating 19a (condition [B]). Alternatively, TFE could be used as an efficient cosolvent for peptide substrates with low solubility in methanol (condition $[\mathbf{C}]$ ), although pure TFE was also a good solvent for the reaction (condition $[\mathbf{D}]$ ). Mechanistically, we suspect that alcohols might facilitate the dehydration of aminal intermediate 13 to form 14 via solventbridged proton transfer (see Supplementary Fig. 65) for our proposed mechanistic model). In comparison to the 1-thioisoindole motif such as in $\mathbf{5}$, which is relatively prone to oxidation by air, the isoindolinimine moiety in compound 19a proved to be very robust in aqueous solvents at $\mathrm{rt}$ under air atmosphere over a wide $\mathrm{pH}$ range (1-12). Heating 19a in PBS buffer ( $\mathrm{pH} 7.3)$ at $60{ }^{\circ} \mathrm{C}$ for $12 \mathrm{~h}$ gave little decomposed product. However, significant amounts of the acyclic isoindolinone side product $(>30 \%)$ was formed when 19a was heated in the same buffer at $100{ }^{\circ} \mathrm{C}$ for $2 \mathrm{~h}$ (see Supplementary Fig. 69 for details).

The OPA-2amines-mediated end-to-side macrocyclization was efficient for peptide substrates of a wide range of ring sizes and AA compositions, affording the products in excellent regioselectivity in $10 \mathrm{~min}$ (Fig. 3b). Most of the reactions were completed within $2 \mathrm{~min}$. Two examples that demonstrate the flexibility permitted by the reaction with regards to the number of spacing AA units are seen in the formation in high yield of $\mathbf{2 1}$ bearing no spacing AA units and 35 bearing more than 10 AA units between the N-terminus and the Lys residue. Except for Cys, all unprotected proteinogenic AA units, such as Arg (24), His (30), Trp (33), Tyr (24), Ser (24), and Glu (31), were well tolerated. D-AA units, such as D-Phe (28), could also be incorporated. Notably, the reaction of substrates containing Cys resulted in a complex mixture of products (e.g., 28). Except for Pro, which bears a secondary amino group, a variety of proteinogenic AAs can be placed at the $\mathrm{N}$-terminus. The conversion of large peptide substrates was more favorable with TFE as a cosolvent (condition $[\mathbf{C}]$ ), owing to its superior solubilizing ability compared to $\mathrm{MeOH}$.

We next set out to synthesize crosslinked peptides with potential biomimetic activity or active medical properties. For example, compound 29 was prepared in excellent yield to mimic the integrin inhibitor cyclo(RGDfK). The reaction of the 18-mer human $\beta$-melanocyte-stimulating hormone ( $\beta$-MSH 5 -22) afforded cyclized product 34 in $30 \%$ yield. An analog of the diabetes drug Liraglutide (without the lipophilic conjugate on the side chain of Lys20) gave 35 in $48 \%$ yield at $1 \mathrm{mM}$ reaction concentration. Based on LC analysis, a slightly cleaner transformation was observed when the reaction was conducted at $5 \mu \mathrm{M}$ (LC trace 8). Finally, the reaction of 33-mer glucagon-like peptide 2 (GLP-2), featuring 28 spacing AA units, gave 33 in $28 \%$ yield, along with acyclic isoindolinone side products. Using peptide substrate $\mathrm{H}$-Ala-Val-Gly-Lys- $\mathrm{NH}_{2}$ 26, the macrocyclization reaction was also amenable to a range of OPA analogs (see 3640, Fig. 3c). Importantly, using 41 as a model compound, we showed that OPA-2amines peptide stapling can be performed in 
<smiles>CC(N)C(=O)NC(Cc1c[nH]c2ccccc12)C(=O)NCC(=O)NC(CCCCN)C(N)=O</smiles>

$18 \mathrm{H}$-Ala-Trp-Gly-Lys- $\mathrm{NH}_{2}$ (TFA salt) (1.0 equiv)

$\underset{\mathrm{OPA}(1.0 \text { equiv) }}{\longrightarrow}$
[A] PBS buffer $(\mathrm{pH}$ 8.0) / MeOH (1/1)
[B] $\mathrm{H}_{2} \mathrm{O} / \mathrm{MeOH}(1 / 1), \mathrm{DIPEA}(3$ equiv)
[C] $\mathrm{H}_{2} \mathrm{O} / \mathrm{TFE}(1 / 1), \mathrm{DIPEA}(3$ equiv)
[D] TFE, DIPEA (3 equiv)
[18] : $5.0 \mathrm{mM}, \mathrm{rt}, 10 \mathrm{~min}$ for all conditions

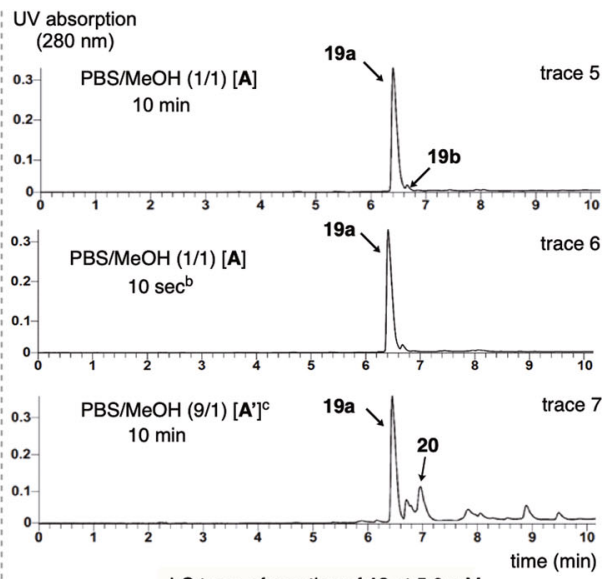

LC trace of reaction of $\mathbf{1 8}$ at $5.0 \mathrm{mM}$

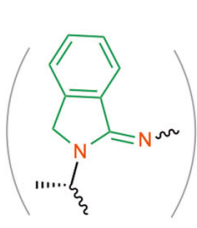

$19 b$
minor regioisome<smiles>C[C@H](N=C1c2ccccc2CN1CCCC[C@H](NC(=O)CNC(=O)[C@H](Cc1c[nH]c2ccccc12)NC(N)=O)C(=O)O)C(N)(O)O</smiles>

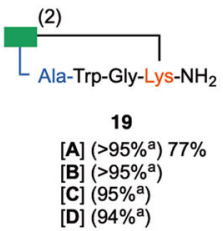

( $a / b>20 / 1$ under all conditions)

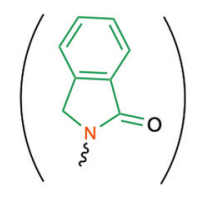

20

)

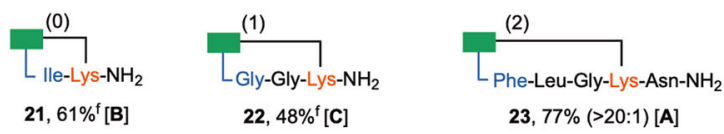

$22,48 \%{ }^{\mathrm{f}}[\mathrm{C}]$
$23,77 \%(>20: 1)[$ A]

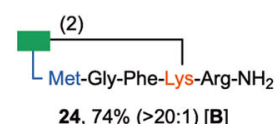

$24,74 \%(>20: 1)[B]$
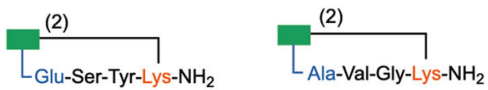

27, $79 \%(>20: 1)$ [A]

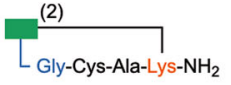

28, complex mixture [A-D]

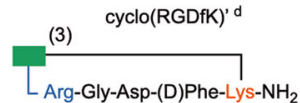

29, 75\% (> 20:1) [A]

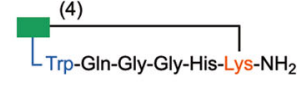

30, $72 \%(>20: 1)$ [C]
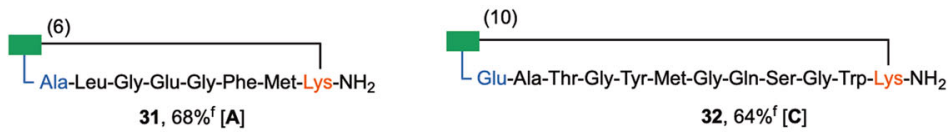

32, $64 \%{ }^{\mathrm{f}}[\mathrm{C}]$

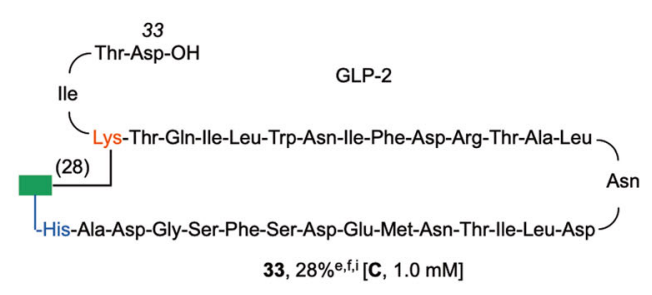

$33,28 \%$ ef,i [C, $1.0 \mathrm{mM}]$
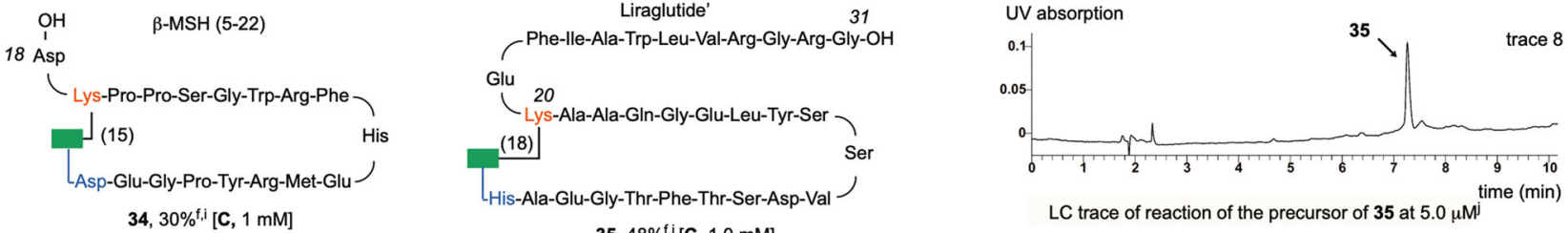

$35,48 \%$ fi, [C, $1.0 \mathrm{mM}]$

c)

c)

26 H-Ala-Val-Gly-Lys-NH<smiles>Fc1ccc2c(c1)C1=NCCC[C@@H]1CN2</smiles>

36, $75 \%^{9}[\mathrm{C}]$<smiles>Brc1ccc2c(c1)C1=NCCC[C@@H]2C1</smiles>

37, $78 \%{ }^{\mathrm{g}}[\mathrm{C}]$<smiles>C1=NC[C@@H]2CN1Cc1sccc12</smiles>

$38,57 \%{ }^{9}[\mathrm{C}]$<smiles>c1ccc2cc3c(cc2c1)C1=NCCCN2C[C@H]1C32</smiles>

$39,80 \%[C]$<smiles>NCCc1ccc2c(c1)C1=NCCCCN1C2</smiles>

40, $76 \%{ }^{9}[\mathrm{C}]$

d)
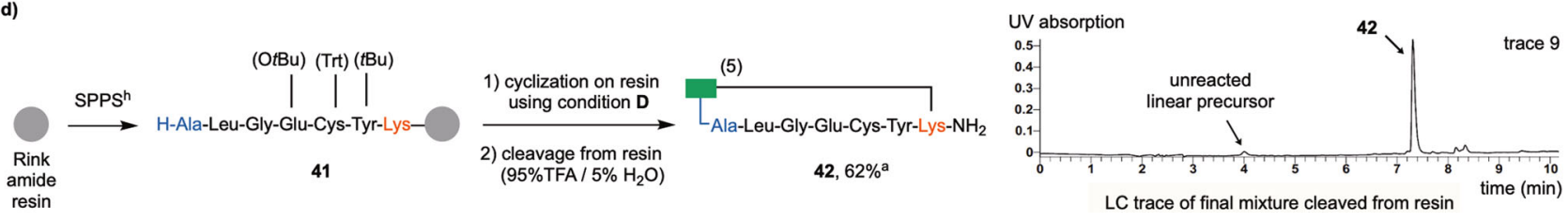

Fig. 3 OPA-2amines reaction for end-to-side stapling of unprotected peptides. a Reaction of model substrate $\mathbf{1 8}$ with OPA. $\mathbf{b}$ Influence of spacing units and amino acid composition. c Cyclization of $\mathrm{H}$-Ala-Val-Gly-Lys- $\mathrm{NH}_{2} \mathbf{2 6}$ with OPA analogs. d Cyclization on solid phase. Yield is based on the HPLC isolated product of reaction conducted at $5.0 \mathrm{mM}$ concentration and $0.001-0.05 \mathrm{mmol}$ scale unless otherwise specified. The number of spacing $A A$ units is shown in parentheses next to the green rectangle symbol that represents the isoindolinimine motif. The ratio of two regioisomers is shown in parentheses next to product yield. a LC-estimated yield. ${ }^{\mathrm{b}} \mathrm{A}$ small aliquot of the reaction mixture was taken and quenched with mixed solvents of $\mathrm{H}_{2} \mathrm{O} / \mathrm{MeOH} / \mathrm{HCO}_{2} \mathrm{H}$

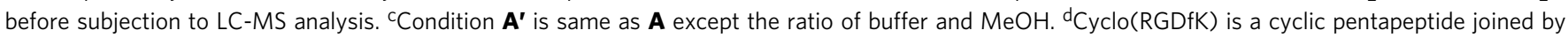
five backbone amide bonds. eThe acyclic isoindolinone side product was formed in about $40 \%$ LC yield. ${ }^{\mathrm{f}}$ The ratio of regioisomers was difficult to

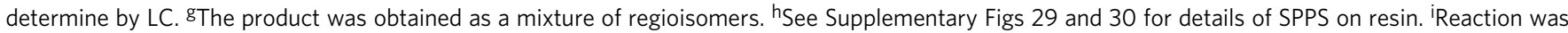

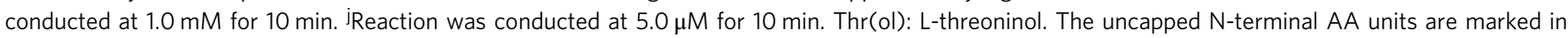
ocean blue, the lysine units and amino groups are marked in red, the OPA reagent and isoindolinimine core are marked in green. 
a)<smiles>CC(=O)NC(CCCCN)C(=O)NC(Cc1c[nH]c2ccccc12)C(=O)NC(C)C(=O)NC(CC(C)C)C(=O)NC(CCCCN)C(N)=O</smiles>

43 Ac-Lys-Trp-Ala-Leu-Lys-NH 2 (TFA salt) (1.0 equiv)

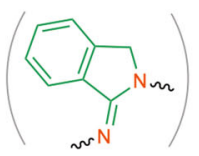<smiles>c1ccc2c(c1)CNC2</smiles>

regioisomer<smiles>CCCCC[C@H](NC(C)=O)C(=O)N[C@@H](Cc1c[nH]c2ccccc12)C(=O)N[C@@H](C)C(=O)N[C@@H](CC(C)C)C(=O)NCC</smiles>

OPA (1.0 equiv)

[A] PBS buffer $(\mathrm{pH} 8.0) / \mathrm{MeOH}(1 / 1)$ [B] $\mathrm{H}_{2} \mathrm{O} / \mathrm{MeOH}(1 / 1)$, DIPEA ( 3 equiv) [B] $\mathrm{H}_{2} \mathrm{O} / \mathrm{MeOH}(1 / 1)$, DIPEA (3 equiv)
[C] $\mathrm{H}_{2} \mathrm{O} / \mathrm{TFE}(1 / 1)$, DIPEA (3 equiv) [C] $\mathrm{H}_{2} \mathrm{O} / \mathrm{TFE}$ (1/1), DIPEA [43]: $5.0 \mathrm{mM}, \mathrm{rt}, 10 \mathrm{~min}$ for all conditions
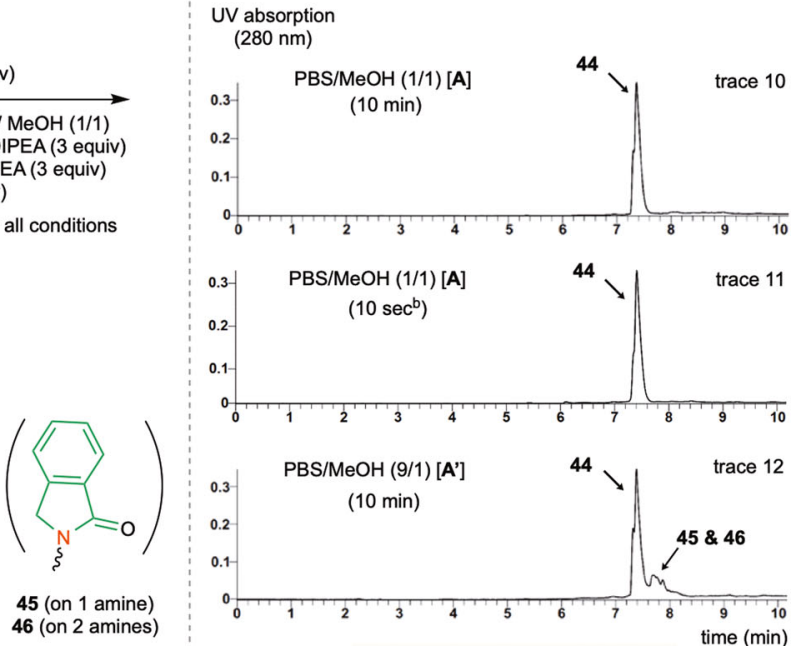

(regioisomers)

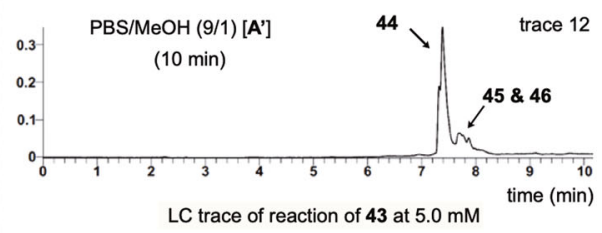

C trace of reaction of $\mathbf{4 3}$ at $5.0 \mathrm{mM}$

b)
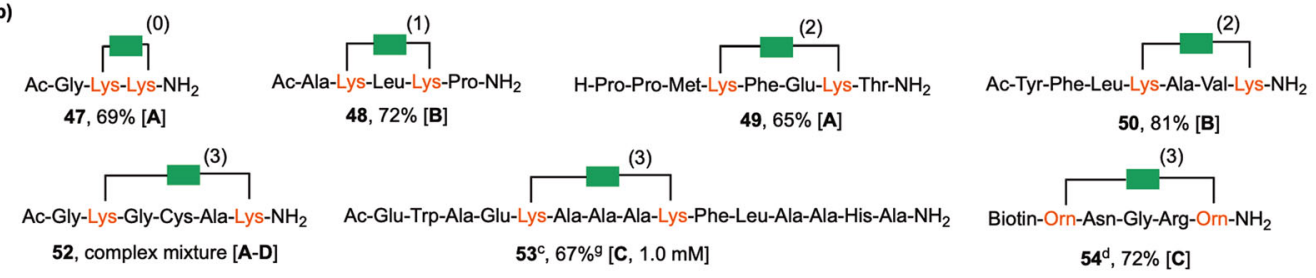

Ac-Tyr-Phe-Leu- $81 \%[$ [B]

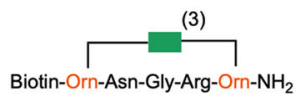
$54^{\mathrm{d}}, 72 \%[\mathrm{C}]$
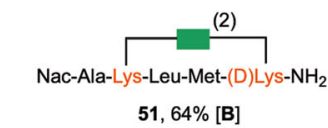

Ac-Gly-Lys-Gly-Cys-Ala-Lys-NH $53^{\mathrm{c}}, 67 \%{ }^{\mathrm{g}}[\mathrm{C}, 1.0 \mathrm{mM}]$
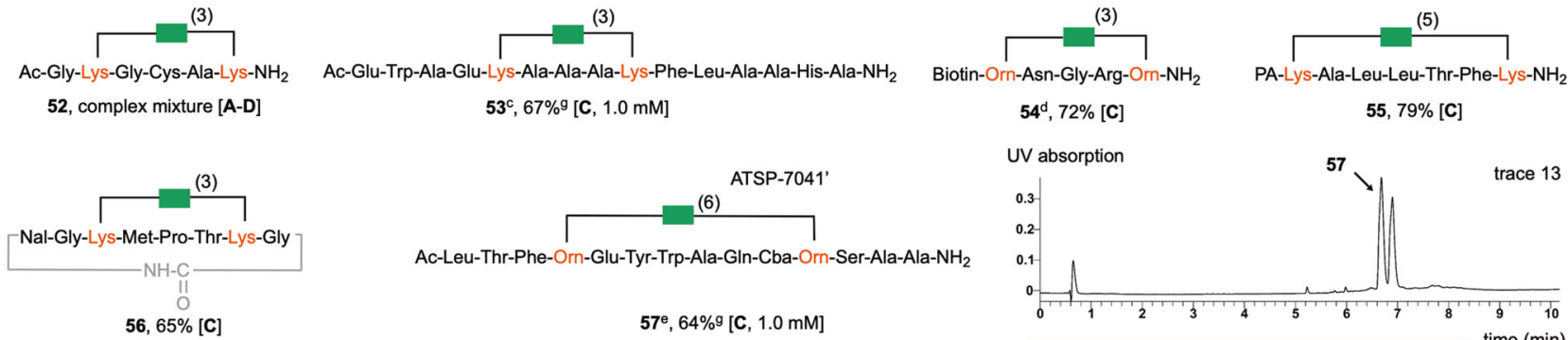

UV absorption

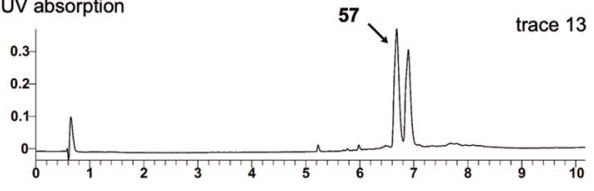

LC trace of reaction of the precursor of 57 at $20.0 \mu \mathrm{M}^{\mathrm{h}}$ time (min)

c)
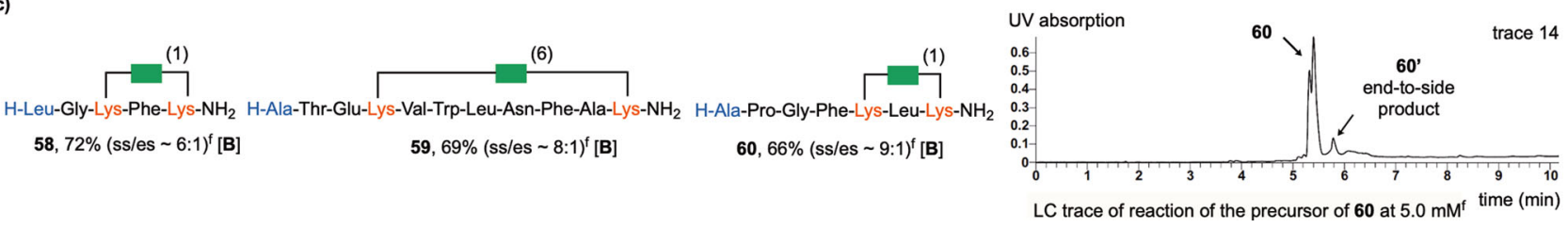

Fig. 4 OPA-2amines reaction for side-to-side stapling of peptides. a Model reaction of $\mathbf{4 3}$. $\mathbf{b}$ Influence of spacing units and amino acid composition. c) Reaction of substrates with free $\mathrm{N}$-terminal $\mathrm{NH}_{2}$. Yield is based on HPLC isolated product of reactions conducted at $5.0 \mathrm{mM}$ concentration and $0.01-$ $0.05 \mathrm{mmol}$ scale unless otherwise specified. All products were obtained as a mixture of regioisomers. ${ }^{a} \mathrm{LC}$-estimated yield. ${ }^{\mathrm{b}} \mathrm{A}$ small aliquot of the reaction mixture was taken and quenched with mixed solvents of $\mathrm{H}_{2} \mathrm{O} / \mathrm{MeOH} / \mathrm{HCO}_{2} \mathrm{H}$ before subjection to LC-MS analysis. ${ }^{\mathrm{C}} \mathrm{Adaption}$ from an $\alpha$ helical sequence of RNase A. dBiotin was attached to the N-terminus. e Adaption from peptide ATSP-7041. ${ }^{f}$ The structures of the major side-to-side (ss) stapled products were confirmed by comparison with the samples prepared from properly protected substrates, see Supplementary Fig. 48 for details. The minor peaks were assigned as the end-to-side (es) products according to molecular weight and their structures have not been vigorously confirmed. The ss/es ratio was estimated by LC-MS analysis. gReaction was conducted at $1.0 \mathrm{mM}$ for $10 \mathrm{~min}$. heaction was conducted at $20.0 \mu \mathrm{M}$ for $10 \mathrm{~min}$. Nal: L-1-Naphthylalanine. PA: picolinic acid. The uncapped N-terminal AA units are marked in ocean blue, the lysine units and amino groups are marked in red, the OPA reagent and isoindolinimine core are marked in green.

conjunction with solid-phase peptide synthesis (Fig. 3d). Treatment of partially protected peptide substrate $\mathbf{4 1}$ on resin with OPA in TFE (condition [D]) followed by TFA-mediated deprotection and cleavage gave $\mathbf{4 2}$ bearing a free Cys residue in excellent conversion and selectivity (LC trace 9).

Side-to-side stapling of peptides by OPA-2amines condensation. As shown in Fig. 4a, the OPA-2amines reaction could also enable highly efficient side chain to side chain (side-to-side) stapling of linear peptides via two Lys side chains under the standard conditions already described in end-to-side stapling. For example, the reaction of pentapeptide $\mathbf{4 3}$ with an Ac-protected $\mathrm{N}$ terminus with OPA (1.0 equiv) in $10 \mathrm{~min}$ formed the cyclic product 44 in excellent yield (LC trace 10). Notably, the product was obtained as a mixture of two regioisomers in a close ratio due to the similar reactivity of the two Lys side chains. As seen in the end-to-side stapling of 17, stapling of 43 at $5 \mathrm{mM}$ can be completed within 10 seconds (LC trace 11). Stapling of 43 at $50 \mu \mathrm{M}$ for 2 min gave almost identical results (see Supplementary Fig. 32). Stapling of $\mathbf{4 3}$ also worked well at relatively high concentration, such as $50 \mathrm{mM}$, whereas a small amount of doubleOPA side product ( $5 \%$ based on LC analysis) was formed 
when the concentration was further increased to $100 \mathrm{mM}$ (see Supplementary Fig. 67). Similar to end-to-side stapling, using alcohol as a cosolvent facilitated the desired macrocyclization. A considerable amount of acyclic isoindolinone side products 45 and 46 were formed when the ratio of $\mathrm{MeOH}$ vs buffer was lowered from 1:1 to 1:9 (condition [ $\left.\mathbf{A}^{\prime}\right]$, LC trace 12).

Substrates with a wide range of spacing units between the two Lys residues were well tolerated, and all proteinogenic AAs except for Cys are compatible (Fig. 4b). The reaction was adaptable to various unnatural AA units such as ornithine (Orn, 57) and capping groups such as biotin (54) could be incorporated. As shown by 49 , the secondary amine group in N-terminal Pro remained unaffected by the reaction. The utility of the side-toside peptide stapling technique was demonstrated by the synthesis of various biomimetic analogs. For example, the reaction of a 15-mer peptide sequence derived from RNase A gave 53 in excellent yield ${ }^{46}$. Moreover, the macrocyclization of a 14-mer sequence derived from ATSP-704147, a peptide inhibitor of the p53-MDM2 interaction, at $1 \mathrm{mM}$ gave 57 in $64 \%$ yield via side-to-side stapling of two Orn side chains. As shown in LC trace 13, slightly cleaner transformation was observed when the reaction were conducted at $20 \mu \mathrm{M}$ concentration. The macrocyclization reaction can be used to generate complex bicyclic products as exemplified by the reaction of 56, a macrolactam peptide substrate with two Lys, which undergoes cyclization to afford the bicyclic product in excellent yield and selectivity. As shown by 58-60, the stapling of substrates bearing two Lys side chains and unblocked N-terminal amine groups proceeded with high side-to-side vs end-to-side selectivity, indicating the higher reactivity of the Lys side chain than the N-terminus in our reaction system (Fig. 3c) ${ }^{45}$.

Further extension of isoindolinimine products. In addition to the excellent stability of the macrocyclic isoindolinimine products in an aqueous medium at $\mathrm{rt}$ over a wide range of $\mathrm{pH}$ values, they could also undergo further chemoselective reaction with certain electron-deficient $\pi$ electrophiles under the same stapling conditions, enabling the highly efficient and facile construction of complex structures from simple linear precursors in a one-pot fashion (Fig. 5a). For example, when $\mathbf{2 6}$ was reacted with a large excess of OPA (3.0 equiv) in a $\mathrm{H}_{2} \mathrm{O} / \mathrm{TFE}$ mixture (condition [C]) for $30 \mathrm{~min}$, the double-OPA macrocyclization product $\mathbf{6 1}$ was cleanly formed in $73 \%$ yield. However, the success of the condensation reaction depends strongly on the nature of the aldehyde reaction partner, and other aldehydes, such as benzaldehyde, methylglyoxal, and glyoxylic acid, gave little 61-like product (see Supplementary Fig. 50). Similar to the reactivity of the 1-thio-isoindole product generated by the OPA-amine-thiol reaction, 26 can likewise undergo further addition reactions with appropriate electrophiles. For example, treatment of 27 with $\mathrm{N}$-methyl maleimide 62 (3.0 equiv) ${ }^{22}$ for $15 \mathrm{~min}$ gave the $\mathrm{C}_{3^{-}}$ alkylation product 63 in $68 \%$ yield. Alkyne DMAC 66 can act in a manner analogous to maleimide for the one-pot addition reaction, but the reactivity towards DMAC strongly depends on the reaction partner. Hence, whereas 27 reacts sluggishly giving 67 in low yield, under the same conditions the linear substrate $\mathrm{H}$-PheLeu-Gly-Lys-Asn- $\mathrm{NH}_{2}$ reacts to give the addition product in good yield (67\%, see Supplementary Fig. 59 for details). Moreover, $\beta$ nitrostyrene 64 is also an efficient acceptor for the sequential reaction using 27 as the substrate, forming $\mathbf{6 5}$ in high yield. It should be noted that similar results were obtained for this onepot procedure using either condition $[\mathbf{A}]$ or [B]. Reactions of $\mathbf{2 7}$ with methyl acrylate, vinyl sulfones, and 4-phenyl-3H-1,2,4triazoline-3,5(4H)-diones gave little desired products, whereas the reaction with aryl diazonium salts gave a complex mixture (see Supplementary Fig. 62).

In general, isoindoles are more reactive than indoles. The plain isoindole predominately exists in the $2 \mathrm{H}$-isoindole form, which can tautomerize to $1 \mathrm{H}$-isoindole at very small concentration via equilibrium (Fig. 5b) ${ }^{48}$. However, the ratio of the two tautomers can vary depending on the substitutions on isoindoles. In contrast with the 1-thiol-isoindole core generated by the OPA-thiol-amine reaction, the isoindole core generated by the OPA-2amines reaction predominantly exists in the isoindolin-1-imine form $\mathbf{I}$, which can be viewed as a variant of $1 H$-isoindole. Previously studies have shown that $2 \mathrm{H}$-isoindoles can undergo Diels-Alder (D-A) type of reaction with dienophiles across the C1-C3 and electrophilic substitution reaction at $\mathrm{C} 1 / \mathrm{C} 3^{49-51}$. We propose that isoindolinimine I can tautomerize to 1-aminoisoindoline II, which is generated in small concentration but likely much more reactive that II. II can undergo Diels-Alder reaction with dienophile such as maleimides to generate cycloadduct III, which immediately rearranges to give the final C3 substitution product IV possibly due to the strain around the $\mathrm{C} 1$ aminal center of III $^{50}$. NMR and LC-MS-based analysis of the model reaction of 68 with 62 did not identify any stable cycloadduct intermediate in our hands (see Supplementary Fig. 54 for details). Alternatively, II can undergo nucleophilic addition to alkene electrophiles to directly give IV. Nucleophilic addition of II to the aldehyde group of OPA followed by dehydration is likely responsible for the formation of the corresponding C3 condensation products $(\text { see 61 })^{51}$.

As outlined in Fig. 5c, sequential addition of OPA and FITCconjugated maleimide $\mathbf{7 0}$ to the RGD-containing sequence $\mathbf{6 9}$ gave the fluorescently labeled product 71 in $61 \%$ yield over two steps (LC trace 16). The usefulness of our one-pot approach could even be extended to a three-step sequential addition of OPA, 4bromo-OPA 72, and methoxyamine to substrate 26, giving the triple-modified product $\mathbf{7 4}$ in good yield (Fig. 5d).

Through reinvestigating the classical OPA-amine-thiol condensation chemistry, we found that OPA quickly reacted with two primary alkyl amino groups to selectively form isoindolinimine products, whose chemical reactivity has been rarely explored. The OPA-2amines-mediated macrocyclization reaction provides a practical and broadly applicable method for the fast stapling of unprotected peptides via the reaction of the amino groups from two AA residues and an OPA or OPA analogs in both side-to-side and end-to-side fashions under mild conditions. Moreover, the resulting isoindolinimine linkage can undergo further reaction with electron-deficient $\pi$ electrophiles under the same cyclization conditions in one pot. Overall, the reported stapling methodology and one-pot sequential addition reactions offer a powerful strategy to selectively modify unprotected peptides and construct diverse macrocyclic structures with readily accessible peptide precursors and inexpensive reagents.

\footnotetext{
Methods

Typical procedure for both end-to-side and side-to-side peptide stapling. To a solution of linear peptide precursor $18(32.7 \mathrm{mg}, 0.05 \mathrm{mmol}, 1.0$ equiv) in $10.0 \mathrm{~mL}$ of PBS buffer ( $\mathrm{pH} 8.0$ ) / MeOH (1:1), OPA was added (1.0 equiv, $50 \mu \mathrm{L}$ of $1 \mathrm{M}$ stock solution in $\mathrm{MeOH})$. The reaction mixture was stirred in an air atmosphere for $10 \mathrm{~min}$ at $\mathrm{rt}$. The reaction mixture was then purified by semipreparative HPLC in two batches with a reverse-phase $\mathrm{C} 18$ column $\left(\mathrm{H}_{2} \mathrm{O}\right.$ and $\mathrm{MeCN}$ with $0.1 \%$ $\mathrm{HCO}_{2} \mathrm{H}$ as eluents) to give the product $19 \mathrm{a}$ as a yellowish powder after lyophilization $(23.2 \mathrm{mg}, 77 \%)$.
}

\section{Data availability}

Detailed synthetic procedures, additional control experiments, compound characterization, LC-MS trace, and NMR spectra are available within the Article and its Supplementary Information. 
a)

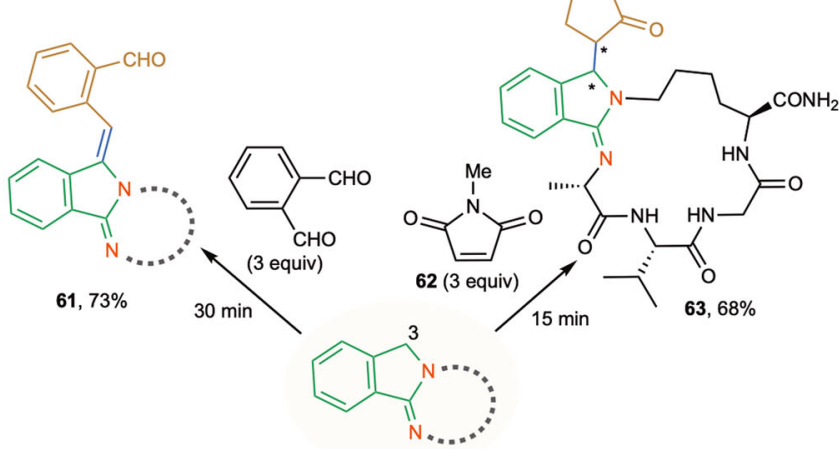

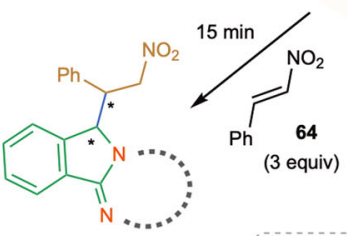

$65,71 \%$

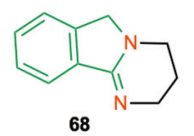

(see its reaction with 62 in SI) ${ }^{\text {a }}$

c)
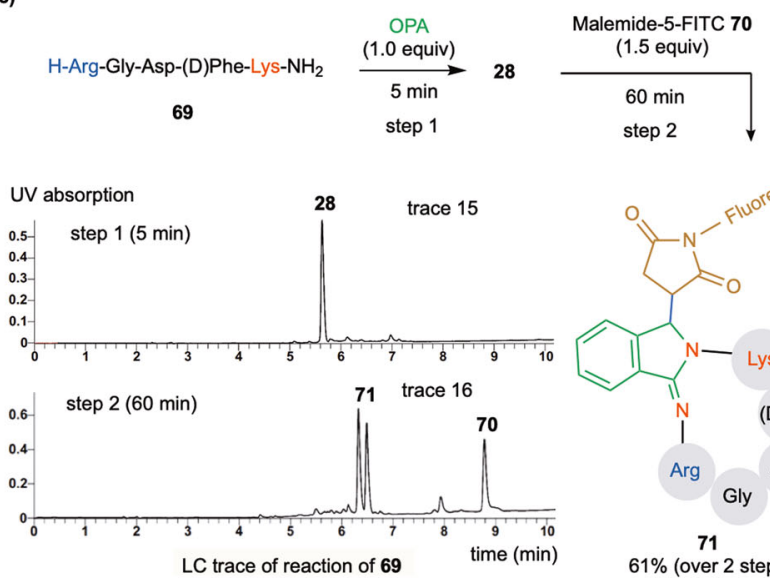

LC trace of reaction of 69

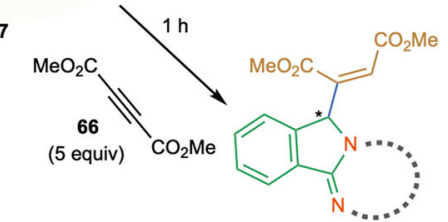

$67,32 \%$

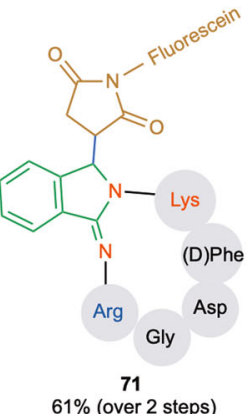

b)

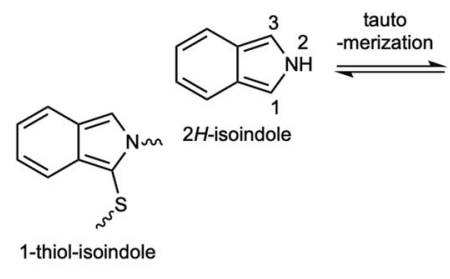<smiles>C1=NCc2ccccc21</smiles>

1H-isoindole

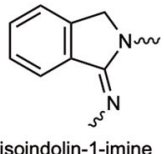

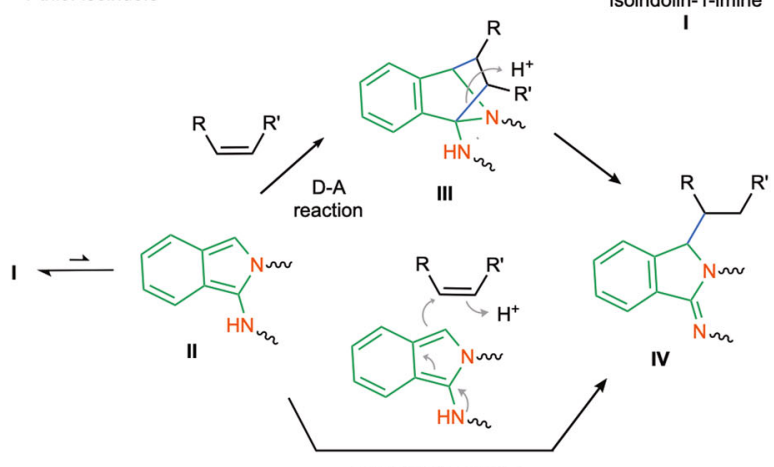

nucleophilic addition

d)
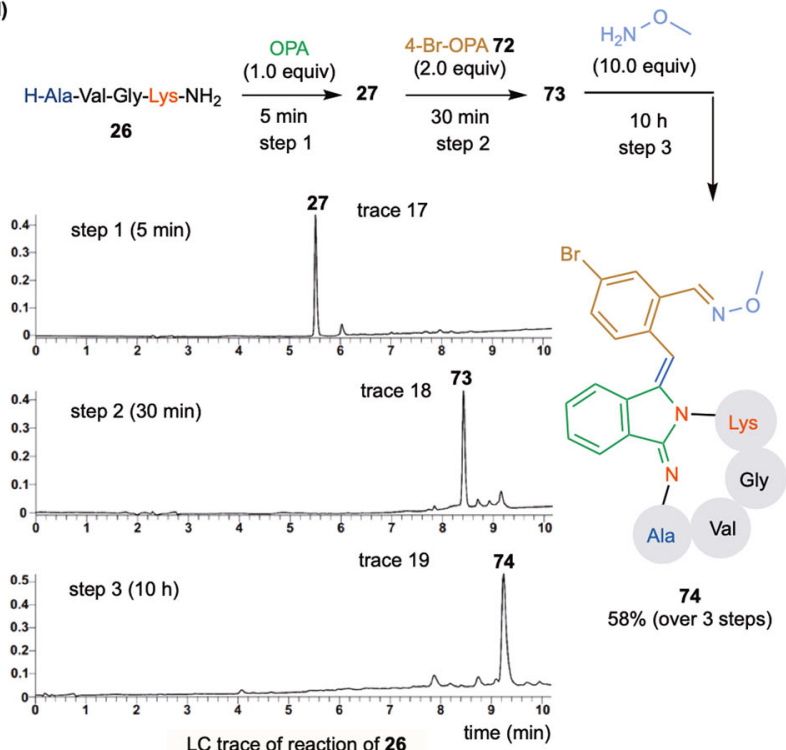

74

$58 \%$ (over 3 steps)

Fig. 5 Facile extension of stapled product with electron-deficient $\boldsymbol{\pi}$ electrophiles. All reactions were conducted under condition $[\mathbf{C}]\left(\mathrm{H}_{2} \mathrm{O} / \mathrm{TFE}(1: 1)\right.$, DIPEA, rt) at $5.0 \mathrm{mM}$ concentration. a Extension of $\mathbf{2 7}$. Isolated yield over two steps in one pot. Stereochemistry of the double modification products has not been determined. $\mathbf{b}$ Possible reaction pathways of the isoindolin-1-imine moiety. c Fluorescent labeling of $\mathbf{6 9}$ via double modification in one pot. $\mathbf{d}$ Triple modification of $\mathbf{2 5}$ via sequential additions in one pot. a See Supplementary Figures 51-54 for a detailed analysis of the reaction of model substrate $\mathbf{6 8}$ with 62. The uncapped $\mathrm{N}$-terminal $\mathrm{AA}$ units are marked in ocean blue, the lysine units and amino groups are marked in red, the OPA reagent and isoindolinimine core are marked in green, and the linkages between isoindolinimine and electrophiles are marked in blue.

Received: 16 July 2021; Accepted: 10 December 2021;

Published online: 14 January 2022

\section{References}

1. Kent, S. B. H. The critical role of peptide chemistry in the life sicences. J. Pept. Sci. 21, 136-138 (2015).

2. Spicer, C. D. \& Davis, B. G. Selective chemical protein modification. Nat. Commun. 5, 4740 (2014).

3. Krall, N., da Cruz, F. P., Boutureira, O. \& Bernardes, G. J. L. Site-selective protein-modification chemistry for basic biology and drug development. Nat. Chem. 8, 103-113 (2016).

4. Lau, Y. H., de Andrade, P., Wu, Y. \& Spring, D. R. Peptide stapling techniques based on different macrocyclisation chemistries. Chem. Soc. Rev. 44, 91-102 (2015).
5. Derda, R. \& Jafari, M. R. Synthetic cross-linking of peptides: molecular linchpins for peptide cyclization. Protein Pept. Lett. 25, 1-25 (2018).

6. Reguera, L. \& Rivera, D. G. Multicomponent reaction toolbox for peptide macrocyclization and stapling. Chem. Rev. 119, 9836-9860 (2019).

7. White, C. J. \& Yudin, A. K. Contemporary strategies for peptide macrocyclization. Nat. Chem. 3, 509-524 (2011).

8. Vinogradov, A. A., Yin, Y. \& Suga, H. Macrocyclic peptides as drug candidates: recent progress and remaining challenges. J. Am. Chem. Soc. 141, 4167-4187 (2019).

9. Wang, C. K. \& Craik, D. J. Designing macrocyclic disulfide-rich peptides for biotechnological applications. Nat. Chem. Biol. 14, 417-427 (2018).

10. Lawson, K. V., Rose, T. E. \& Harran, P. G. Template-constrained macrocyclic peptides prepared from native, unprotected precursors. Proc. Natl Acad. Sci. USA 110, E3753-E3760 (2013).

11. Frost, J. R., Scully, C. C. \& Yudin, A. K. Oxadiazole grafts in peptide macrocycles. Nat. Chem. 8, 1105-1111 (2016).

12. Rojas, A. J. et al. Divergent unprotected peptide macrocyclisation by palladium-mediated cysteine arylation. Chem. Sci. 8, 4257-4263 (2017). 
13. Girvin, Z. C., Andrews, M. K., Liu, X. \& Gellman, S. H. Foldamer-templated catalysis of macrocycle formation. Science 366, 1528-1531 (2019).

14. Gagnon, C. et al. Biocatalytic synthesis of planar chiral macrocycles. Science 367, 917-921 (2020).

15. Chalker, J. M., Bernardes, G. J. L., Lin, Y. A. \& Davis, B. G. Chemical modification of proteins at cysteine: opportunities in chemistry and biology. Chem. Asian J. 4, 630-640 (2009).

16. Heinis, C., Rutherford, T., Freund, S. \& Winter, G. Phage-encoded combinatorial chemical libraries based on bicyclic peptides. Nat. Chem. Biol. 5, 502-507 (2009).

17. Jo, H. et al. Development of $\alpha$-Helical Calpain Probes by Mimicking a Natural Protein-Protein Interaction. J. Am. Chem. Soc. 134, 17704-17713 (2012).

18. Spokoyny, A. M. et al. A perfluoroaryl-cysteine SNAr chemistry approach to unprotected peptide stapling. J. Am. Chem. Soc. 135, 5946-5949 (2013)

19. Assem, N., Ferreira, D. J., Wolan, D. W. \& Dawson, P. E. Acetone-Linked. Peptides: A Convergent Approach for Peptide Macrocyclization and Labeling. Angew. Chem., Int. Ed 54, 8665-8668 (2015).

20. Pelay-Gimeno, M., Bange, T., Hennig, S. \& Grossmann, T. N. In situ cyclization of native proteins: structure-based design of a bicyclic enzyme. Angew. Chem. Int. Ed. 57, 11164-11170 (2018).

21. Ceballos, J., Grinhagena, E., Sangouard, G., Heinis, C. \& Waser, J. Cys-Cys and Cys-Lys Stapling of Unprotected Peptides Enabled by Hypervalent Iodine Reagents. Angew. Chem., Int. Ed 60, 9022-9031 (2021).

22. Zhang, Y., Zhang, Q., Wong, C. T. T. \& Li, X. Chemoselective peptide cyclization and bicyclization directly on unprotected peptides. J. Am. Chem. Soc. 141, 12274-12279 (2019).

23. Todorovic, M. et al. Fluorescent isoindole crosslink (FlICk) chemistry - a rapid, user-friendly stapling reaction. Angew. Chem., Int. Ed. 58, 14120-14124 (2019).

24. Tanaka, K. et al. A Submicrogram-scale protocol for biomolecule-based PET imaging by rapid $6 \mathrm{p}$-azaelectrocyclization: visualization of sialic acid dependent circulatory residence of glycoproteins. Angew. Chem., Int. Ed. 47, 102-105 (2008).

25. Cal, P. M. S. D. et al. Iminoboronates: A new strategy for reversible protein modification. J. Am. Chem. Soc. 134, 10299-10305 (2012).

26. Matos, M. J. et al. Chemo- and Regioselective Lysine Modification on native proteins. J. Am. Chem. Soc. 140, 4004-4017 (2018).

27. Malins, L. R. et al. Peptide macrocyclization inspired by non-ribosomal imine natural products. J. Am. Chem. Soc. 139, 5233-5241 (2017)

28. Vasco, A. V. et al. Macrocyclization of peptide side chains by the Ugi reaction: achieving peptide folding and exocyclic $\mathrm{N}$-functionalization in one shot. J. Org. Chem. 80, 6697-6707 (2015).

29. Li, B. et al. Cooperative stapling of native peptides at lysine and tyrosine or arginine with formaldehyde. Angew. Chem., Int. Ed. 60, 6646-6652 (2021).

30. Fujimoto, K., Kajino, M. \& Inouye, M. Development of a Series of CrossLinking Agents that Effectively Stabilize $\alpha$-Helical Structures in Various Short. Peptides. Chem. - Eur. J 14, 857-863 (2018).

31. Lautrette, G., Touti, F., Lee, H. G., Dai, P. \& Pentelute, B. L. Nitrogen Arylation for Macrocyclization of Unprotected Peptides. J. Am. Chem. Soc. 138, 8340-8343 (2016).

32. Takahashi, I. \& Hatanaka, M. Recent progress of phthalimidine synthesis. Heterocycles 45, 2475-2499 (1997).

33. Zuman, P. Reactions of orthophthalaldehyde with nucleophiles. Chem. Rev. 104, 3217-3238 (2004)

34. Thiele, J. \& Schneider, J. Liebigs Annalen 369, 287 (1909).

35. DoMinh, T., Johnson, A. L., Jones, J. E. \& Senise, P. P. Jr. Reactions of phthalaldehyde with ammonia and amines. J. Org. Chem. 42, 4217-4221 (1977).

36. Grigg, R., Gunaratne, H. Q. N. \& Sridharan, V. A Simple one-step synthesis of $\mathrm{N}$-substituted isoindolin-1-ones. diastereofacially selective protonation of an intermediate isoindolinol. J. Chem. Soc., Chem. Commun., 1183-1184 (1985).

37. Alajarin, M., Sanchez-Andrada, P., Lopez-Leonardo, C. \& Alvarez, A. On the mechanism of phthalimidine formation via o-phthalaldehyde monoimines. new $[1,5]-\mathrm{H}$ sigmatropic rearrangements in molecules with the 5-aza-2,4pentadienal skeleton. J. Org. Chem. 70, 7617-7623 (2005).

38. Tung, C. L., Wong, C. T., Fung, E. Y. \& Li, X. Traceless and chemoselective amine bioconjugation via phthalimidine formation in native protein modification. Org. Lett. 18, 2600-2603 (2016).

39. Roth, M. Fluorescence reaction for amino acids. Anal. Chem. 43, 880-882 (1971).

40. Simons, S. S. Jr. \& Johnson, D. F. The structure of the fluorescent adduct formed in the reaction of o-phthalaldehyde and thiols with amines. J. Am. Chem. Soc. 98, 7098-7099 (1976).

41. Simons, S. S. Jr., Ammon, H. L., Doherty, R. \& Johnson, D. F. Structure and properties of a stable isoindole. The dimethyl acetylenedicarboxylate-1- (ethylthio)-2-propylisoindole substitution product. J. Org. Chem. 46, 4739-4744 (1981).

42. Puri, R. N., Bhatnagar, D. \& Roskoski, R. Jr. Inactivation of yeast hexokinase by $o$-phthalaldehyde: evidence for the presence of a cysteine and a lysine at or near the active Site. Biochim. Biophys. Acta 957, 34-46 (1988).

43. Bourdonnec, B. et al. Reporter affinity labels: an o-phthalaldehyde derivative of $\beta$-naltrexamine as a fluorogenic ligand for opioid receptors. J. Med. Chem. 43, 2489-2492 (2000)

44. Li, B., Zhang, J., Li, L. \& Chen, G. A rapid and sensitive method for chiroptical sensing of $\alpha$-amino acids via click-like labeling with o-phthalaldehyde and p-toluenethiol. Chem. Sci. 12, 2504-2508 (2021).

45. Koniev, O. \& Wagner, A. Developments and recent advancements in the field of endogenous amino acid selective bond forming reactions for bioconjugation. Chem. Soc. Rev. 44, 5495-5551 (2015).

46. Kutchukian, S., Yang, S., Verdine, G. \& Shakhnovich, I. All-atom model for stabilization of $\alpha$-helical structure in peptides by hydrocarbon staples. J. Am. Chem. Soc. 131, 4622-4627 (2009).

47. Chang, Y. et al. Stapled $\alpha$-helical peptide drug development: A potent dual inhibitor of MDM2 and MDMX for p53-dependent cancer therapy. Proc. Natl. Acad. Sci. USA 110, E3445-E3454 (2013).

48. Bonnett, R. \& North, S. A. The chemistry of the isoindoles. Adv. Heterocycl. Chem 29, 341-399 (1981).

49. Bonnett, R. \& Brown, R. F. C. Isoindole. Chem. Commun. 393-395 (1972).

50. Bender, C. O., Bonnett, R., and Smith, R. G. The Chemistry of 1,3,4,7Tetramethylisoindole and a Route to the Tetra-benzporphyrin System. J. Chem. Soc. C. 1251-1257 (1970).

51. Bonnett, R., North, S. A., Newton, R. F. \& Scopes, D. I. C. Substitution and addition reactions of isoindoles. Tetrahedron. 39, 1401-1405 (1983).

\section{Acknowledgements}

Grants NSFC-91753124 (GC) and 21725204 (GC) are acknowledged for partial financial support of this work.

\section{Author contributions}

$\mathrm{BL}$ carried out most of reaction optimization and structural determination of products, and prepared the SI. LW, XC, XC, HT, and JZ helped with reaction optimization and expansion of substrate scope. L.L. contributed to the initial development of this project GH supervised part of the experimental studies. GC supervised the entire project, and prepared most of the manuscript.

\section{Competing interests}

The authors declare no competing interests.

\section{Additional information}

Supplementary information The online version contains supplementary material available at https://doi.org/10.1038/s41467-022-27985-7.

Correspondence and requests for materials should be addressed to Li Li or Gong Chen.

Peer review information Nature Communications thanks the anonymous reviewer(s) for their contribution to the peer review of this work.

Reprints and permission information is available at http://www.nature.com/reprints

Publisher's note Springer Nature remains neutral with regard to jurisdictional claims in published maps and institutional affiliations.

Open Access This article is licensed under a Creative Commons Attribution 4.0 International License, which permits use, sharing, adaptation, distribution and reproduction in any medium or format, as long as you give appropriate credit to the original author(s) and the source, provide a link to the Creative Commons license, and indicate if changes were made. The images or other third party material in this article are included in the article's Creative Commons license, unless indicated otherwise in a credit line to the material. If material is not included in the article's Creative Commons license and your intended use is not permitted by statutory regulation or exceeds the permitted use, you will need to obtain permission directly from the copyright holder. To view a copy of this license, visit http://creativecommons.org/ licenses/by/4.0/.

(c) The Author(s) 2022 